\title{
Preview: 1988 MRS Fall Meeting
}

\section{Boston, Massachusetts Events Scheduled November 27-December 3}

\author{
Meeting Chairs: G. Slade Cargill, \\ IBM T.J. Watson Research Center; \\ D. Wayne Goodman, Texas A \& M University; \\ J. Francis Young, University of Illinois
}

The 1988 Fall Meeting of the Materials Research Society will be held at the Boston Marriott and Westin Hotels/Copley Place, Boston, Massachusetts, with events spanning November 27 through December 3.

Program Chairs Slade Cargill, Wayne Goodman, and Francis Young have planned an extensive forum of 24 technical symposia. Over 2,000 papers will be presented, offering a thorough examination of mainstream topics as well as introducing some new ones. In keeping with the spirit of interdisciplinarity, many symposia are featuring joint sessions, and the poster sessions have been expanded to accommodate this increasingly popular medium for individual discussion and in-depth conversation.

Also being offered are 27 specialty, review and survey short courses, an equipment exhibit, and a job placement center. The short courses and equipment exhibitors are listed elsewhere in this issue, and the symposium highlights are described below.

For details about the program and registration, see the 1988 MRS Fall Meeting Preliminary Program, which has been mailed to all MRS members. If you need a Preliminary Program, call the MRS Meetings Department at (412) 367-3003; fax (412) 367-4373.

Special events at the 1988 MRS Fall Meeting include a Forum on the Materials Science and Engineering Study, a plenary address by Prof. Lester C. Thurow, dean of the Massachusetts Institute of Technology's Sloan School of Management, and presentation of the Von Hippel Award and Graduate Student Awards.

\section{Topical Symposia}

Symposium A-Processing and Characterization of Materials Using Ion Beams

Tuesday-Friday, Nov. 29-Dec. 2

Chairs: Lynn E. Rehn, Argonne National Laboratory; Joe E. Greene, University of Illinois; Fred A. Smidt, Naval Research Laboratory.

This symposium will focus on ionsurface interactions, with particular emphasis on film-formation by ion-beamassisted and low-energy primary deposition, and on metastable materials formed by ion bombardment. Approximately 78 oral and 56 poster papers will cover: ionbeam-assisted deposition; beam-induced epitaxy, crystal growth, and interface migration; characterization of ion-beammodified microstructures; amorphization and metastable phase formation; ion implantation/ion beam mixing; and properties of ion-beam-modified materials. A joint plenary session on Surfaces is planned with Symposium B; a joint session on Ion and Laser Modified Surfaces is planned with Symposium S. Invited speakers include J-E. Sundgren, B.W. Dodson, J.R. McNeil, J. Dieleman, I. Yamada, D.M. Follstaedt, J.M.E. Harper, J.M. Poate, and J.W. Rabalais.
Symposium B-Laser and Particle Beam Chemical Processes on Surfaces

Tuesday-Friday, Nov. 29-Dec. 2

Chairs: A. Wayne Johnson, Sandia National Laboratories; G.L. Loper, Aerospace Corporation; T.W. Sigmon, Stanford University.

Approximately 68 oral and 34 poster papers will consider the following topics: laser-induced deposition and etching; laser-assisted chemical modification and doping of solids; ion-beam and electronbeam assisted deposition and etching; beam-induced decomposition processes for surface-adsorbed molecules; laserinduced ablation of polymeric materials; plasma formation of reactants for deposition and etching; diagnostics and modeling of the fundamentals of beam-induced process chemistry and physics; deep UV and $x$-ray synchrotron processing of thin films; in situ processing of thin films; and technological implications of beaminduced processing and process monitoring. A joint plenary session is planned with Symposium A. Invited speakers include J-E. Sundgren, B.W. Dodson, J.R. McNeil, J. Dieleman, K. Kompa, C.I.H. Ashby, R.F. Miracky, V.M. Donnelly, A.F. Bernhardt, R.M. Osgood Jr., Ian W. Boyd, and K.F. Jensen

Symposium C-Thin Films: Stresses and Mechanical Properties

Monday-Wednesday, Nov. 28-30

Chairs: John C. Bravman, Stanford University; William D. Nix, Stanford University; David M. Barnett, Stanford University; David A. Smith, IBM T.J. Watson Research Center.

Approximately 65 oral presentations will focus on macroscopic or microscopic phenomena from both experimental and theoretical viewpoints. Topics include, but are not limited to thin film microstructures and mechanical properties; in situ deformation studies of thin films; tailored microstructures for control of mechanical properties; intrinsic stresses in thin films; epitaxy; direct observations of defects in thin films; deformation mechanisms in thin films; mechanical testing of thin films; and dfects in thin films. Invited speakers include T. Vreeland Jr., P.A. Flinn, M. Murakami, R.W. Hoffman, F.R. Brotzen, L.B. Freund, J.W. Hutchison, J.B. Pethica, and K. Seshan. 
Symposium D-Advanced Methods for Characterizing the Surfaces/Interfaces of Materials

\section{Monday-Wednesday, Nov. 28-30}

Chairs: I.E. Wachs, Lehigh University; R. Nuzzo, AT\&T Bell Laboratories; A. Madhukar, University of Southern California.

This symposium will bring together researchers in biomaterials, ceramics, catalysts and polymers to consider all three types of interfaces (solid-solid, gas-solid, and liquid-solid). Approximately 33 oral and 41 poster papers will span synchotron radiation studies (EXAFS, NEXAFS, XANES, etc.); optical studies (Raman, IR, etc.); solid state NMR; UHV surface science techniques (EELS, XPS, SIMS, UPS, etc.); electron microscopy studies; Mossbauer studies; and chemical probes. Invited speakers include S.T. Ceyer, T.M.
Duncan, L.H. Dubois, U. Gelius, W. Krakow, K.S. Liang, D.L. Allara, S. Granick, A.L. Harris, J.F. Rabolt, G.M. Whitesides, T.P. Russell, and M. Seul.

\section{Symposium E-Chemical Perspectives of Microelectronic Materials}

\section{Wednesday-Friday, Nov. 30-Dec. 2}

Chairs: Mihal E. Gross, AT\&T Bell Laboratories; John T. Yates Jr., University of Pittsburgh; Joseph Jasinski, IBM T.J. Watson Research Center.

The symposium will highlight a lively mixture of topics, including synthetic and mechanistic studies, gas phase and surface interactions, and preparation and application of novel chemical precursors. Approximately 61 oral and 62 poster papers will cover synthesis of new precursors for mi-

\section{Calendar of Events}

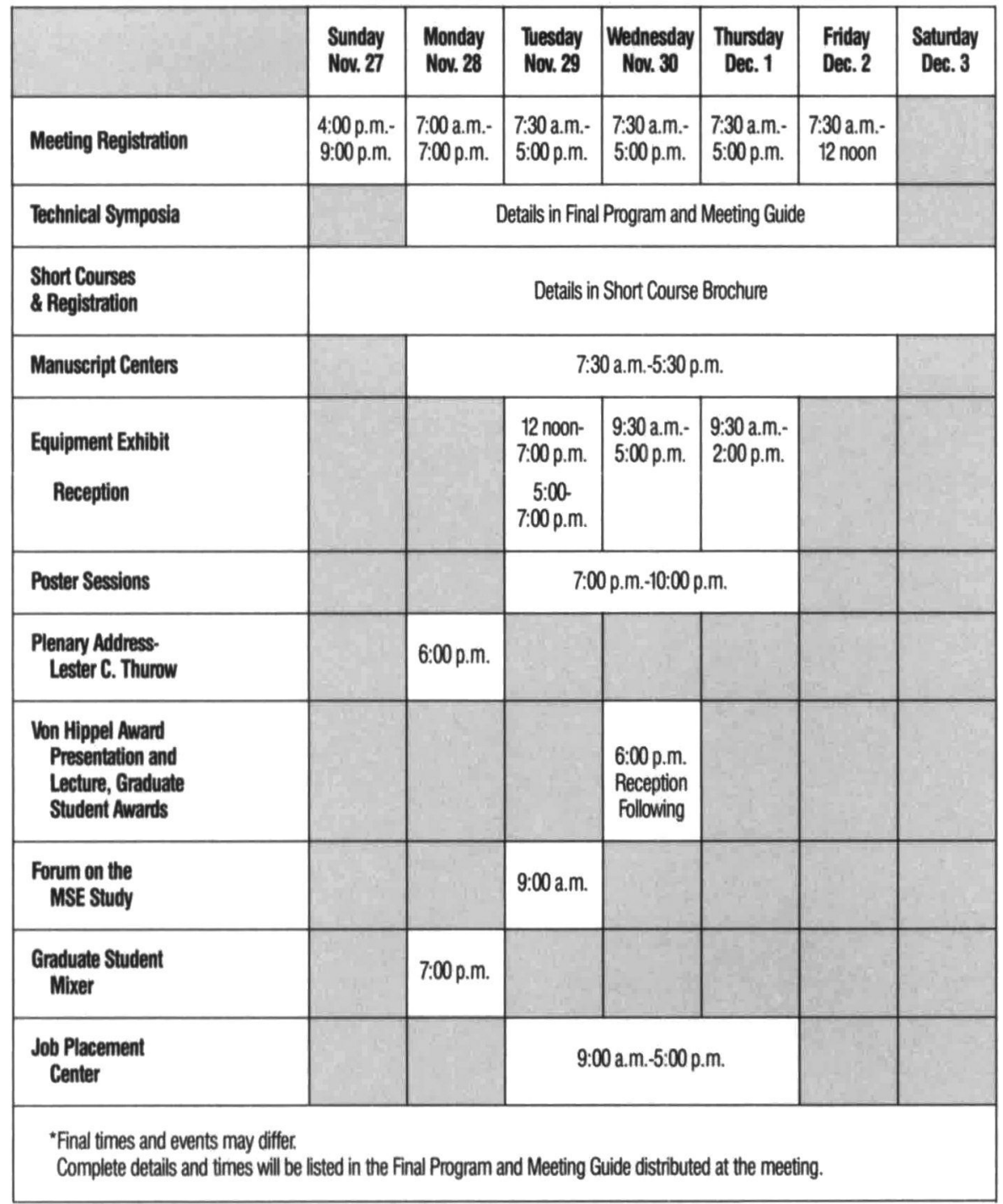

Chairs: Roger Koch, IBM T.J. Watson Research Center; Simon Foner, Massachusetts İnstitute of Technology; John Clarke, University of California, Berkeley.

Approximately 108 oral and 176 poster papers are scheduled to cover both experimental and theoretical topics: new approaches for fabrication of films, wires, and bulk materials; techniques for making Josephson junctions and weak links, including patterning; reproducibility and stability of high $T_{c}$ superconductors; measurements of magnetic, electrical, and chemical properties; methods to control the microstructure and composition of these materials, including grain boundary morphology; analysis and measurements of the loss mechanisms, fracture and crack propagation, intergranular conduction, low resistance contacts, etc.; approaches to the integration of the high $\mathrm{T}_{\mathrm{c}}$ materials into conventional technologies (i.e. Si); materials properties and problems critical to device and circuit applications; economic feasibility of applying high $T_{c}$ superconductors; and new types of applications. Invited speakers include A.M. Hermann, S.S.P. Parkin, E.L. Venturini, B. Raveau, B.G. Bagley, Y. Bando, L. Krusin-Elbaum, P. Day, R. Cava, J.B. Torrance, Y. Hidaka, and S. Matsuda.

\section{Symposium G-Multicomponent Ultrafine Microstructures}

Wednesday-Thursday, Nov. 30-Dec. 1 Chairs: B.H. Kear, Rutgers University; D.E. Polk, Office of Naval Research; R.W. Siegel, Argonne National Laboratories.

Approximately 37 oral presentations will address the preparation, characterization and properties of materials having multi- 
component ultrafine microstructures, i.e., nanocrystalline materials having a microstructural scale of 1 to $100 \mathrm{~nm}$. Topics include: new approaches to producing multicomponent ultrafine microstructures; microstructural characterization; mechanical properties; magnetic behavior; electron transport phenomena; interaction with electromagnetic radiation; and potential applications. Invited speakers include T. Tsakalakos, B.M. Gallois, and R.W. Siegel

\section{Symposium H-High Temperature Ordered Intermetallic Alloys}

\section{Tuesday-Thursday, Nov. 29-Dec. 1}

Chairs: C.C. Koch, North Carolina State University; C.T. Liu, Oak Ridge National Laboratory; N.S. Stoloff, Rensselaer Polytechnic Institute; A.I. Taub, General Electric Corporation.

Approximately 69 oral and 61 poster papers will focus on the following specific subjects dealing with ordered alloys: kinetics and theory of ordering; phase stability; mechanical properties; dislocation substructures; welding and fabrication; wear, adhesion and erosion; defects and grain boundaries; environmental cracking; rapid solidification; powder processing, single crystals, structural applications and alloy design; thermomechanical treatment; composites and multiphase intermetallics; and elastic properties. Invited speakers include D. de Fontaine, J.A. Horton, D. Farkas, P. Veyssiere, M.H. Yoo, D.M. Dimiduk, D.L. Anton, S.C. Huang, R.M. German, S.M.L. Sastry, and T. Suzuki.

\section{Symposium I-Liquid Crystal Polymers}

Tuesday-Friday, Nov. 29-Dec. 2 Chairs: Samuel I. Stupp, University of Inlinois at Urbana-Champaign; Claudine Noel, Ecole Superieure de Physique et de Chimie Industrielle; Robert W. Lenz, University of Massachusetts at Amherst.

Approximately 57 oral presentations and 8 posters will highlight the following areas for this emerging class of materials: synthesis of novel main chain and side chain liquid crystal polymers; characterization techniques; theory of liquid crystal polymers; solid state structure and properties; interaction of liquid crystal polymers with surfaces; magnetic and electric field orientation; ferroelectric systems; nonlinear optical properties; processing and rheology; blends and composites involving LCP components; self-assembling systems and lyotropic polymers; and mesogenic biopo- lymers. A joint session on Theory and Calculations is planned with Symposium J. Invited speakers include D.Y. Yoon, F. Dowell, A. Abe, M. Warner, N. Koide, C. Noel, F. Hardouin, R.S. Stein, G. Zerbi, T. Asada, M. Ballauff, S.I. Stupp, A.H. Windle, A. Blumstein, J.H. Wendorff, and M.K. Cox.

\section{Symposium J-Materials Science and Engineering of Rigid-Rod Polymers}

\section{Monday-Friday, Nov. 28-Dec. 2}

Chairs: W. Wade Adams, Air Force Materials Laboratory; Ronald K. Eby, Johns Hopkins University; Donald E. McLemore, Dow Chemical Company.

Approximately 73 oral and 10 poster papers, both theoretical and experimental, will consider a wide variety of topics, including synthesis, chemical and physical structural characterization, processing and properties. Materials in the form of solutions, fibers, film, composites and molecular composites will be discussed. A joint session on Theory and Calculations is planned with Symposium I. Invited speakers include H.F. Mark, F.E. Arnold, J.F. Wolfe, R.C. Evers, W.A. Feld, J.J. Kane, L.R. Dalton, M.H. Litt, B.Gordon III, P.J. Flory (deceased), D.Y. Yoon, F. Dowell, A. Abe, M. Warner, E.C. Chenevey, W.D. Timmons, H.D. Ledbetter, R.W. Lusignea, M. Takayanagi, C. Leung, C.Y.-C. Lee, R.F. Kovar, J.E. Ward, G.C. Berry, A. Keller, Y. Cohen, P.S. Russo, F.E. Karasz, W-F. Hwang, S.J. Krause, H.H. Chuah, D.S. Nelson, D.L. VanderHart, C:A. Gabriel, C.S. Wang, R.J. Farris, S.G. Wierschke, P. Galen Lenhert, R.K. Eby, R.J. Young, S.J. Deteresa, J. Im, I.J. Goldfarb, E. Grant Jones, E.L. Thomas, A.V. Fratini, B.L. Farmer, J.B. Lando, E.J. Roche, D.C. Martin, S.J. Bai, D.R. Ulrich, A.F. Garito, J. Stamatoff, M.A. Druy, J.A. Medrano, N.G. Rondan, P.N. Prasad, M.A. Ratner, L.R. Dalton, J.E. Mark, W.J. Welsh, R.E. Barker, Jr., and S.H. Carr.

\section{Symposium K-Materials Science of Mineralized Biological Tissues}

\section{Tuesday, November 29}

Chairs: Wendell S. Williams, Case Western Reserve University; George Van B. Cochran, Helen Hayes Hospital.

Approximately 17 oral and 6 poster papers will discuss the microstructure, chemistry, mechanical behavior and electrical properties of bone, tooth, shell and other hard tissues. The perspective will be that of materials science, but the biological function of the tissue as it dictates these rela- tions will be kept in focus. Topics include: electron microscopy of shell, bone, and tooth; pore structure of mineralized tissues; studies of chemical composition using SIMS, Auger electron microscopy, electron probe, XPS, etc.; differences in microstructure and chemistry between normal and abnormal bone, especially osteoporotic specimens; insights into the process of mineralization of collagenous tissue; defect chemistry of biological apatite mineral; role of minor organic constituents in affecting surface chemistry and properties; and detection of piezoelectric response (in addition to streaming potential) in mechanically strained bone. Invited speakers include S.E. Doty, C.T. Rubin, W.S. Williams, M. Otter, R.K. Aaron, L.L. Klepinger, and V.J. Laraia.

\section{Symposium L-Graphite Intercalation Compounds: Science and Applications}

Wednesday-Friday, Nov. 30-Dec. 2 Chairs: M.S. Dresselhaus, Massachusetts Institute of Technology; G. Dresselhaus, Massachusetts Institute of Technology; M. Endo, Shinshu University.

Approximately 57 original_oral and 8 poster papers will consider charge transfer and intercalation mechanisms; domains and kinetics; electrochemical intercalation and batteries; ternary compounds; new intercalated materials; structure and phase transitions; lattice modes; electronic structure and optical properties; transport properties; superconductivity and magnetism; fibers, composites and glassy carbon; and new phenomena and applications. Invited speakers include $H$. Zabel, Y. Nishina, Y. Iye, M. Suzuki, G. Chouteau, L. Piraux, M. Inagaki, J.R. Gaier, H. Touhara, R. Schlogl, R. Saito, W.R. Datars, and A. Mizoguchi.

\section{Symposium M-Solid State Ionics}

Monday-Friday, Nov. 28-Dec. 2

Chairs: Gholamabbas Nazri, General Motors Research Laboratory; Robert A. Huggins, Stanford University; Duward F. Shriver, Northwestern University; P.T. Wu, Industrial Technology Research Institute.

This symposium will focus on the synthesis, characterization and testing of solid state ionics, covering all experimental, theoretical and applied aspects. Approximately 84 oral presentations will discuss solid state inorganic ion conductors; ionically conductive polymers; theory of ionic motion in solids; superionic conductors in energy conversion devices; superionic conductors in electrochromic devices; and 
solid state sensors and thin film devices. Invited speakers include T. Takahashi, W. Weppner, J.R. Akridge, J. Schoonman, M.M. Thackeray, W. Fischer, P. Vashishta, W.A. Curtin, K. Funke, C.A. Angell, R.P. Buck, M.A. Ratner, M. Balkanski, R. Frech, A. Belzner, C.A. Angell, N.J. Dudney, A. Petric, G.C. Farrington, H-C. zur Loye, J. Livage, J. Maier, S. Crouch-Baker, J.B. Goodenough, P. Hagenmuller, J.M. Tarascon, J. Rouxel, J.H. Kennedy, M. Schreiber J.B. Bates, and H.L. Tuller.

\section{Symposium N-Fractal Aspects of Materials: Disordered Systems}

\section{Tuesday-Friday, Nov. 29-Dec. 2}

Chairs: David A. Weitz, Exxon Research \& Engineering; Leonard M. Sander, University of Michigan; Benoit B. Mandelbrot, IBM

Approximately 75 oral and 40 poster papers will explore modern methods of describing the structure and physics of highly disordered materials and systems. The use of fractal concepts will be a unifying theme, but other descriptive techniques will also be featured. Discussion will cover flow and porous media, glasses and quasicrystals, colloidal systems and ceramics, spinodal decomposition and of dynamical aspects of turbulence. Topics include nonequilibrium growth and pattern formation, chaos, turbulence and instabilities, aggregation and gelation scattering, porous media, fractal measures, fractons and locali ation, surface roughness, and new applications of fractal concepts to materials science. Invited speakers include D.A. Kessler, H.Z. Cummins, A.J. Libchaber, P. Wiltzius, M. Rabaud, D.J. Srolovitz, J. Klafter, K.R. Sreenivasan, W.I. Goldburg, L.M. Schwartz, H. Scher, M.F. Shlesinger, R. Merlin, A. Arneodo, R. Klein, B.J. Ackerson, P.N. Pusey, A.J. Hurd, S.K. Sinha, Y.R. Termonia, and T.A. Witten.

\section{Symposium O-Fly Ash and Coal Conversion By Products: Characterization, Utilization and Disposal V}

Wednesday-Thursday, Nov. 30-Dec. 1 Chairs: E.E. Berry, E.E. Berry Technical Consulting Ltd.; R.T. Hemmings, E.E. Berry Technical Consulting Ltd; G.J. McCarthy, North Dakota State University.

The seventh MRS symposium on this topic will continue to emphasize use of modern materials characterization tools to understand structure, properties and reactions during utilization or disposal. Approximately 32 oral papers will cover residues from advanced $\mathrm{SO}_{2}$ control, re- source recovery, ash benefication, engineering applications, and groundwater quality at ash disposal sites. Three joint sessions on Porosity and Permeability of Blended Cements, on Porosity and Properties of Blended Cements, and on PorosityProperty Relationships are planned with Symposium P. Invited speakers include P.L. Pratt, F.P. Glasser, S. Diamond, and H. Hojaji.

\section{Symposium P-Pore Structure and Permeability of Cementitious Materials}

Monday-Wednesday, Nov. 28-Nov. 30 Chairs: Lawrence R. Roberts, W.R. Grace \& Co.; Jan P. Skalny, W.R. Grace \& Co.

Approximately 55 oral papers will address the importance of porosity, pore structure, permeability and diffusivity on the properties and environmental stability of cement-based materials, with special emphasis on the underlying science and measurement techniques. Topics include fundamentals of porosity, diffusivity, and permeability; experimental techniques to measure porosity, diffusivity, and permeability; relationship of concrete properties to porosity, diffusivity and permeability; new avenues to control durability through engineering of porosity. Three joint sessions on Porosity and Permeability of Blended Cements, on Porosity and Properties of Blended Cements, and on PorosityProperty Relationships are planned with Symposium O. Invited speakers include P.L. Pratt, F.P. Glasser, S. Diamond, and H. Hojaji. Invited speakers include R.W. Rice, P. Sheng, R.F. Feldman, R.E. Green, Jr., D. Winslow, W. Hansen, K.L. Scrivener, D.M. Roy, M. Moranville-Regourd, C.M. Hansson, J.L. Conca, R.L. Day, F.P. Glasser, and S. Diamond.

\section{Symposium Q-Characterization of the Structure and Chemistry of Defects in Materials}

Monday-Tuesday, Nov. 28-29

Chairs: Bennett C. Larson, Oak Ridge National Laboratory; Manfred Ruhle, University of California; David N. Seidman, Northwestern University.

Approximately 35 oral and 79 poster papers will provide a forum for examining results and techniques related to studies of point defects, defect aggregates, line defects, interfaces, grain boundaries, and surface defects. Emphasis will be placed on comparing investigative tools and cross-correlation of results through the selection of invited speakers and round-table discussion periods. Techniques will span
TEM, HREM and analytical electron microscopy; field-ion, atom probe and scanning tunneling microscopy; $x$-ray, neutron and electron diffraction; EXAFS; scanning auger and $x$-ray photoelectron spectroscopy; ion, positron and nuclear methods, etc. A joint session on atomic imaging of defects is planned with Symposium R. Invited speakers include $\mathrm{H}$.J. Wollenberger, G. Martin, J.N. Israelachvili, C.P. Flynn, A.H. Heuer, R.W. Balluffi, A. Bourret, R.M. Feenstra, and D.N. Seidman.

\section{Symposium R-High Resolution Microscopy of Materials}

\section{Tuesday-Thursday, Nov. 29-Dec. 1}

Chairs: William Krakow, IBM Corporation; Fernando A. Ponce, Xerox Corporation; David J. Smith, Arizona State University.

This symposium will provide an overview of a broad range of subject areas to show the state-of-the-art in atomic level imaging techniques and applications. Approximately 45 oral and 21 poster papers will span TEM, STM, and field-ion microscopy; materials areas such as surfaces, interfaces, grain boundaries, point defects, short range order, fine particles, and quasi crystals; and technologically important areas such as electronic and packaging materials, catalysts, magnetic, glassy, ceramic, and alloy materials. Emphasis will be placed on high resolution techniques and analysis. Instrumentation will be featured, allowing individuals and manufacturers to present the latest advancement in atomiclevel imaging techniques. A joint session on Atomic Imaging of Defects is planned with Symposium Q. Invited speakers include A. Bourret, R.M. Feenstra, D.N. Seidman, K. Takayanagi, U. Dahmen, K. Hiraga, J.C. Barry, C.B. Carter, T.E. Mitchell, M.M. Kersker, M.T. Otten, and M. Kubozoe.

\section{Symposium S-New Materials Approaches to Tribology: Theory and Applications}

\section{Tuesday-Friday, Nov. 29-Dec. 2}

Chairs: Larry E. Pope, Sandia National Laboratories; Larry Fehrenbacher, Technology Assessment \& Transfer, Inc., Ward $O$. Winer, Georgia Institute of Technology.

Approximately 64 oral and several poster papers will emphasize the tribology of solid surfaces in extreme environments such as ultrahigh vacuum and high or cryogenic temperatures. The theory of friction and wear at the molecular level will be included. Topics include atomic and molecular dynamics of sliding surfaces; evaluation of material surfaces; surface modification 
of materials; advanced lubricants and tribocomposites; ceramics and light weight bearing materials; extreme environments; applications-mechanisms and trends; and tribological evaluation of materials. Invited speakers include L.L. Fehrenbacher, P.D. Fleischauer, M. Todd, J. Ferrante, H.M. Pollock, J.M. Georges, D.M. Follstaedt, J.N. Israelachvili, A. Banerjea, U. Landman, W.O. Winer, G.M. McClelland, S. Ramalingam, K.-H. Habig, I.L. Singer, P.D. Fleischauer, E.W. Roberts, S. Jahanmir, and M.N. Gardos.

\section{Symposium T-Atomic Scale Calculations in Materials Science}

\section{Monday-Wednesday, Nov. 28-30}

Chairs: J. Tersoff, IBM T.J. Watson Research Center; D. Vanderbilt, Harvard University; V. Vitek, University of Pennsylvania.

Approximately 46 oral and 47 poster papers will concentrate on two particularly active areas-quantum mechanical calculations of total energy, and direct simulation of relatively complex systems and processes such as melting and solidification, MBE growth, and extended defects, usually using empirical interatomic potentials. All microscopic calculations of materials properties will be considered as well as contributions to the development of methods. Topics include calculations of structural and electronic properties and energetics of crystals, defects, amorphous materials, etc.; methods, whether empirical or from first principles, for calculating materials properties; and simulations of the properties of materials at finite temperatures, or of nonequilibrium processes in materials preparation. Invited speakers include S.G. Louie, M.I. Baskes, J.D. Joannopoulos, R.M. Martin, M.S. Duesbery, S.P. Chen, P.D. Bristowe, M.L. Klein, Chris G. Van De Walle, K.C. Pandey, and A. Zunger.

\section{Symposium U-Nondestructive Monitoring of Materials Properties}

Monday-Wednesday, Nov. 28-30 Chairs: John Holbrook, BattelleColumbus; Jean Bussiere, National Resource Council, Canada.

This symposium will emphasize the interaction and collaboration of materials scientists with NDE physicists in order to promote advances in the ability to ascertain with nondestructive techniques the mechanical properties of materials (as well as time-dependent changes in properties).
Approximately 51 oral presentations will explore NDE techniques to monitor properties for process control, monitoring of microstructural aging phenomena that lead to reduced service life or margin of safety, and NDE techniques that can monitor those microstructural changes. Topics include industry/government needs in NDE damage monitoring; NDE techniques to detect materials aging or damage; NDE techniques to determine microstructure of mechanical properties; models of microstructural effects on NDE excitations; deconvolution methods; and experimental NDE studies of aging/ damage of materials. Invited speakers include L.J. House, Anmol S. Birring, A.J. Allen, J-P. Monchalin, B.J. Overton, J.S. Heyman, C. Gault, H.J. Maris, and D.O. Thompson.

\section{Symposium V-Synchrotron Radiation in Materials Research}

Monday-Wednesday, November 28-30 Chairs: John H. Weaver, University of Minnesota; John Gland, Exxon Research and Engineering Company; Roy Clarke, University of Michigan.

This symposium will bring together leading scientists who use synchrotron radiation across a broad range of materials research. Approximately 46 invited and contributed presentations will describe the status of new results obtained using synchrotron radiation techniques. Some presentations will be tutorial, stressing the opportunities for cutting-edge research and the challenges associated with effective utilization of the next generation of insertion-device-based sources. Scientific issues include new opportunities in materials research with ultrahigh brightness sources; chemical kinetics and catalysis; structure of surfaces, interfaces, and multilayers; electronic properties of surfaces, interfaces, and multilayers; $x$-ray microscopy and lithography; and crystallography and small angle scattering. Invited speakers include D.E. Moncton, P.M. Horn, C.R. Safinya, J.L. Erskine, T.-C. Chiang, G. Meitzner, A. Fontaine, D.H. Templeton, M. Hart, J.B. Hastings, C.J. Sparks, and D.M. Shinozaki.

Symposium $\mathbf{W}$-Advances in Materials, Processing and Devices in III-V Compound Semiconductors

Monday-Friday, Nov. 28-Dec. 2 Chairs: Devendra K. Sadana, IBM T.J. Watson Research Center; Lester Eastman, Cor- nell University; Russell Dupuis, AT\&T Bell Laboratories.

An extensive schedule of 115 oral papers will explore novel materials preparation techniques, processing and device concepts covering physical, chemical and electrical characterization. Topics include heteroepitaxy and Si/III-V integration; novel growth techniques for III-V compounds: bulk and eptiaxial layers; ion implantation/annealing: diffusion of dopants, defect formation; capping, decapping, ambient effects on surface morphology, decomposition during processing; metal-semiconductor interfaces and reactions; and novel device structures. Invited speakers include T.F. Kuech, A. Ourmazd, S. Mahajan, T.Y. Tan, N. Chand, R.G. Wilson, J.P. Donnelly, S.S. Lau, T. Sands, H.-T. Yuan, and M.E. Kim.

\section{Symposium $X$-Frontiers of Materials Research, A Symposia Crossing All Symposia}

Monday-Thursday, Nov. 28-Dec. 1 Chair: Rustum Roy, Pennsylvania State University.

This luncheon-time series will consist of 30 to 40 -minute lectures given by leaders in a field. Monday's session will focus on "Case Studies in the History of Materials Research." Subsequent sessions include presentations by H.C. Gatos, H. Mark, E.W. Collings, K.C. Ludema, H. Hiebner, and J.B. MacChesney.

\section{Symposium Y-Selected Topics in Electronic Materials}

\section{Wednesday-Friday, Nov. 30-Dec. 2}

Chairs: B.R. Appleton, Oak Ridge National Laboratory; W.L. Brown, AT\&T Bell Laboratories; D.K. Biegelsen, Xerox; J.A. Knapp, Sandia National Laboratories.

This symposium will provide a one-day forum for pesentation of new research results in three areas of current interest: (1) silicon-on-insulator, epi insulators and buried metals (buried oxide, nitride, carbide; lateral zone melting; epi fluorides; epi, poly and amorphous buried metals); (2) silicides and silicon interfacial phenomena (silicide formation, structure and electrical properties; multilayers; oxide and polysilicon interfaces); and (3) metastable phases and structures and fast transient processing (pulsed laser melting and recrystalization; interface instabilities; high concentration impurity effects in melting and resolidfication). Invited speakers include $\mathrm{F}$. Namavar and $\mathrm{H}$. Ishiwara. 